ANL-6804

Chemistry

(TID-4500, 28th Ed.)

AEC Research and

Development Report

ARGONNE NATIONAL LABORATORY

9700 South Cass Avenue

Argonne, Illinois 60440

FIELD EMISSION FROM

SINGLE CRYSTALS OF GRAPHITE

by

G. Montet, M. Hoch, and G. Hennig

Solid State Science Division

February 1964

Operated by The University of Chicago

under

Contract W-31-109-eng-38

with the

U. S. Atomic Energy Commission 


\section{DISCLAIMER}

This report was prepared as an account of work sponsored by an agency of the United States Government. Neither the United States Government nor any agency Thereof, nor any of their employees, makes any warranty, express or implied, or assumes any legal liability or responsibility for the accuracy, completeness, or usefulness of any information, apparatus, product, or process disclosed, or represents that its use would not infringe privately owned rights. Reference herein to any specific commercial product, process, or service by trade name, trademark, manufacturer, or otherwise does not necessarily constitute or imply its endorsement, recommendation, or favoring by the United States Government or any agency thereof. The views and opinions of authors expressed herein do not necessarily state or reflect those of the United States Government or any agency thereof. 


\section{DISCLAIMER}

Portions of this document may be illegible in electronic image products. Images are produced from the best available original document. 
TABLE OF CONTENTS

$\underline{\text { Page }}$

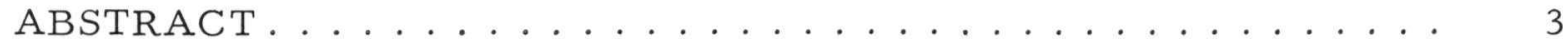

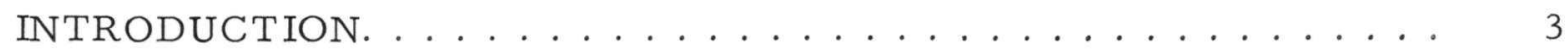

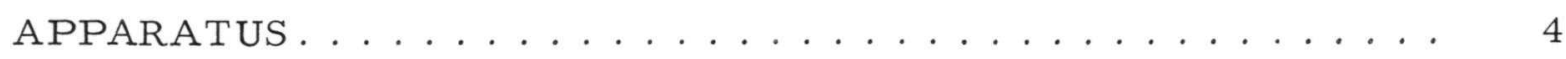

EXPERIMENTS AND RESULTS. . . . . . . . . . . . . . . 5

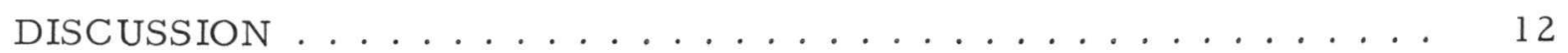

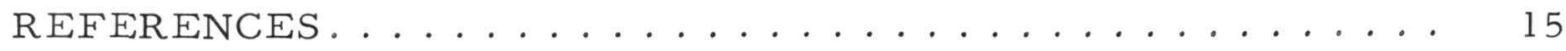




\section{LIST OF FIGURES}

No. Title

$\underline{\text { Page }}$

1. Platelet of Graphite Used as Emitting Tip. . . . . . . . . . 4 4

2. Typical Emission Pattern from Graphite "Knife-edge" . . . . 6

3. Effect of Heating on Emission Pattern . . . . . . . . . . 7

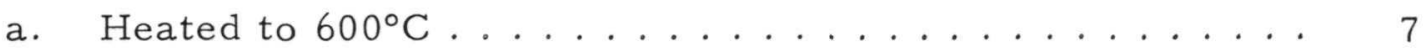

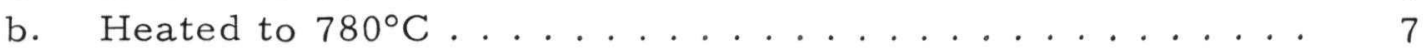

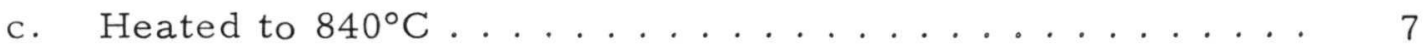

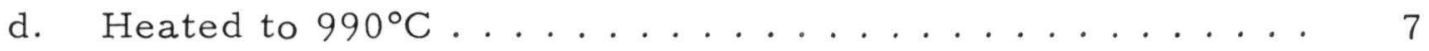

4. Effect of Electric Field on Emission Pattern. . . . . . . . 8

a. Emission at $6.7 \mathrm{kV} \ldots \ldots \ldots \ldots$

b. Emission at $7.9 \mathrm{kV} \ldots \ldots \ldots \ldots \ldots$

c. Emission at $8.5 \mathrm{kV} \ldots \ldots \ldots \ldots$

d. Emission at $9.3 \mathrm{kV} \ldots \ldots \ldots . \ldots \ldots$

5. Fowler-Nordheim Plot .................. 9

6. Effect of Heating on Emission Pattern ............ 10

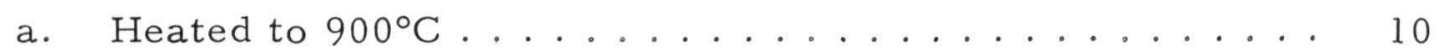

b. Heated to $1500^{\circ} \mathrm{C} \ldots \ldots \ldots \ldots \ldots$

c. Heated to $1800^{\circ} \mathrm{C} \ldots \ldots \ldots \ldots \ldots$

d. Heated to $2000^{\circ} \mathrm{C} \ldots \ldots \ldots \ldots \ldots$

7. Effect of Oxygen on Emission Pattern ............ 11

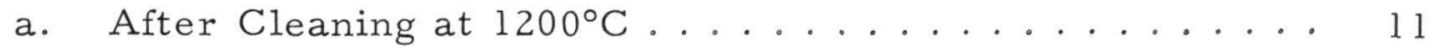

b. After Exposure to 1-micron Air Pressure ......... 11

c. After Cleaning at $1200^{\circ} \mathrm{C} \ldots \ldots \ldots \ldots \ldots \ldots \ldots$

8. Hexagonal Emission Pattern. . . . . . . . . . . . . . 12

9. "Developed" Structure of "Knife-edge" of Graphite....... 13 


\title{
FIELD EMISSION FROM SINGLE CRYSTALS OF GRAPHITE
}

by

\author{
G. Montet, M. Hoch, \\ and G. Hennig
}

\begin{abstract}
The surface conditions of graphite have been studied with a field-emission microscope. The emitting tips were "knife-edges" of graphite platelets made by a technique developed in this Laboratory. The emissions characteristic of clean edges and of edges covered by an oxide film were studied, and some qualitative information of relative work functions of these surfaces was obtained. Attempts to extend these observations are described.
\end{abstract}

\section{INTRODUCTION}

The field-emission microscope has proved to be a valuable tool in the study of the surfaces of solids. (1) The most important feature of such a microscope is the emitting tip, which is usually hemispherical in form with irregularities of atomic dimensions only. Such smoothness can be attained only by high-temperature annealing in an ultra-high vacuum, and massive field emitters have been constructed successfully only from conductors with high melting points, although emission from "whiskers" of various substances has been observed.(2) This requirement has limited the application of the field-emission microscope to the study of such refractory substances as tungsten, molybdenum, and tantalum. Adsorption and desorption of oxygen, barium, thorium, and many other adsorbates have been studied.(3) In addition, many observations have been made of carbon deposited on tungsten and tantalum, (4) and the typical hexagonal pattern of emission from the carbide phase has been detected.

It appears, however, that no observations of field emission of electrons from graphite have been reported; thus, when, during the course of some studies on catalytic oxidation of single crystals of graphite, (5) a technique was developed which made possible the production of sharp "knifeedges" of graphite, it was considered desirable to make some observations on the field emission of electrons from these single-crystal platelets of graphite. Since the knife-edges are regions sharp in one dimension only, the c-direction of the crystal, it was realized that magnification would be obtained in one dimension only; however, it appeared possible that 
something of value about the surface conditions of graphite might be learned by observation of the field-emission "pattern."

The knife-edges of graphite, as usually prepared, were covered with an oxide film. This could be removed by heating in high vacuum. Thus, both clean and oxide-coated surfaces could be studied. By observing the emission from these surfaces and the emission from surfaces deliberately contaminated with various substances, it was hoped that some knowledge of the surface structure of graphite crystals might be gained. Such knowledge would be very useful in the interpretation of many of the characteristic surface properties of graphite.

\section{APPARATUS}

The field-emission microscopes used in these experiments were constructed in our Laboratory by standard procedures. (2) The graphite emitters were made by selective oxidation of crystals in a mixture of chlorine and oxygen, or by flame-etching in the core of a gas-oxygen torch. Either method produces a characteristic platelet, such as is shown in photomicrograph of Figure 1. These platelets were mounted in the microscope by using various supporting arrangements constructed of tungsten.

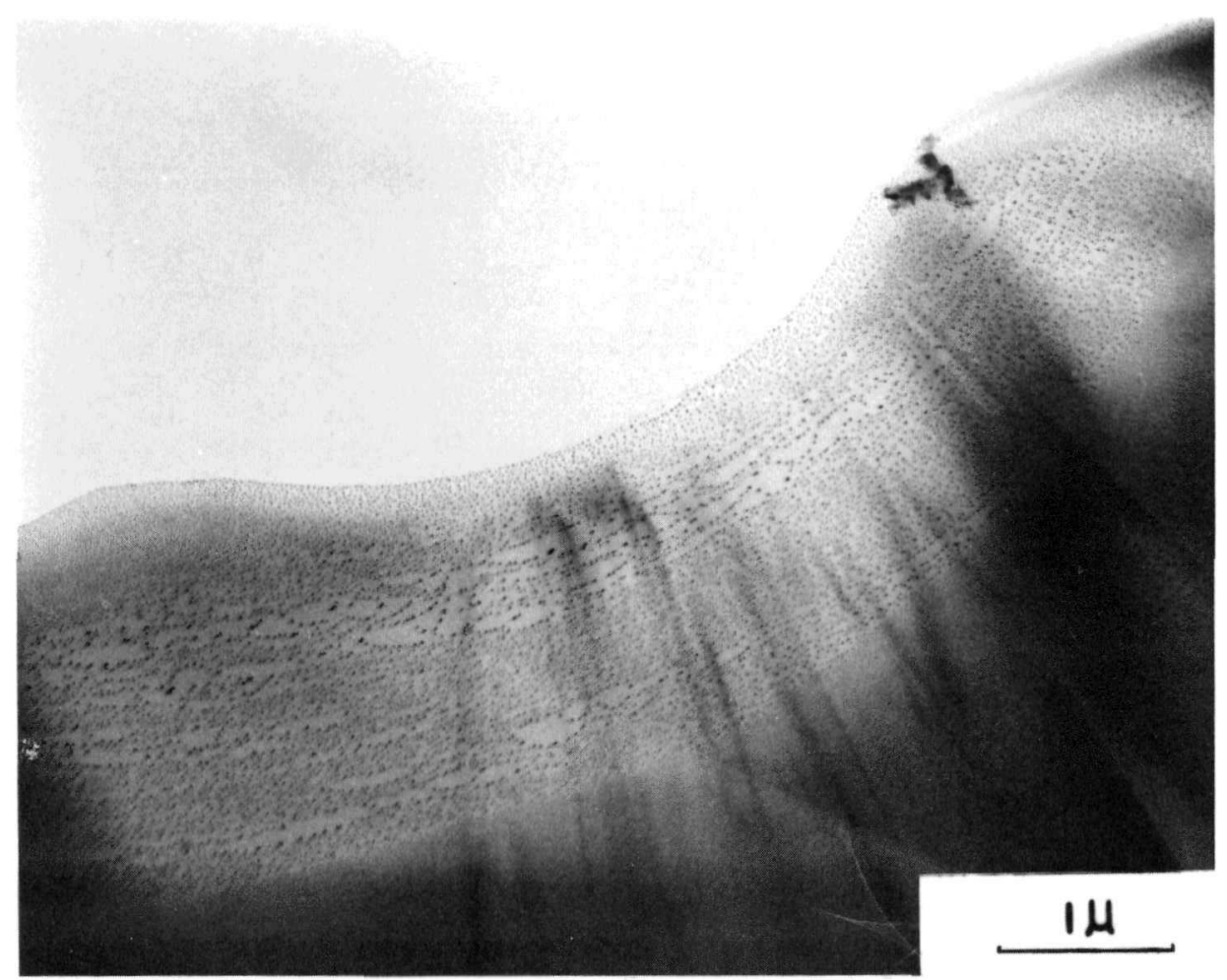

Fig. 1. Platelet of Graphite Used as Emitting Tip 
The cleaning of the emitting surface presented some problems. In the early experiments the platelets were clamped between relatively massive tungsten jaws and the entire assembly was heated by an induction coil surrounding the microscope. The maximum temperature attainable by this method was $\sim 1200^{\circ} \mathrm{C}$; this proved to be insufficient to clean the surfaces. In later experiments the platelets were clamped within a loop of tungsten wire which could be heated by passage of an electric current; this procedure resulted in a temperature of $\sim 2000^{\circ} \mathrm{C}$ at the knife-edge presumably high enough to remove the oxide film.

In a few experiments, finely pointed emitters of tungsten or tantalum were used. These were made by electrolytic etching in the proper bath: sodium nitrite for tungsten, and a mixture of concentrated sulfuric and hydrofluoric acids for tantalum. Thin films of carbon were deposited on these tips by various means to be described later, and electron emis sion through the film was observed.

\section{EXPERIMENTS AND RESULTS}

The early experiments constituted a survey of the effects of pretreatment, mounting, heating, and ion bombardment of the emitters on the emission pattern observed.

The first emitters tried were slivers of graphite crystals etched as described above. In some cases the platelets were further oxidized in oxygen or ozone, in some cases heated to $\sim 700^{\circ} \mathrm{C}$ in an inert atmosphere; however, these treatments did not markedly affect the emission, so in most experiments the graphite platelets were simply etched in the chlorineoxygen mixture or in the oxidizing cone of a small gas-oxygen torch to form the required knife-edge.

Originally the platelets were secured to a tungsten rod by means of a tungsten spring clamp fitted with a sliding collar to tighten the jaws against the graphite. The pressure so exerted caused many twins (6) to form, and the resulting emission pattern indicated that the crystal sometimes exfoliated, i.e., the layer planes separated into discrete packets. The crystals were then fastened to the tungsten rod (in a few cases, a platinum rod) with various adhesives. Among the adhesives used were gold, platinum, sauereisen cement, and aquadag; all of these gave similar results except for spurious spots appearing in the emission when aquadag was used. That the aquadag mounting was emitting electrons, presumably from small protrusions, was confirmed by making some runs in which tungsten tips were coated with aquadag. These produced a pattern consisting of many double lines oriented in various directions. These preliminary experiments indicated that freshly prepared etched platelets held in a simple spring clip of 
sheet tungsten emitted the most consistent pattern, and subsequent experiments were carried out using this emitting system. The results of these experiments are given below.

A typical emission pattern of a freshly prepared knife-edge of graphite is shown in Figure 2. Magnification in only one direction is obtained due to the linear extent of the knife-edge. The characteristic

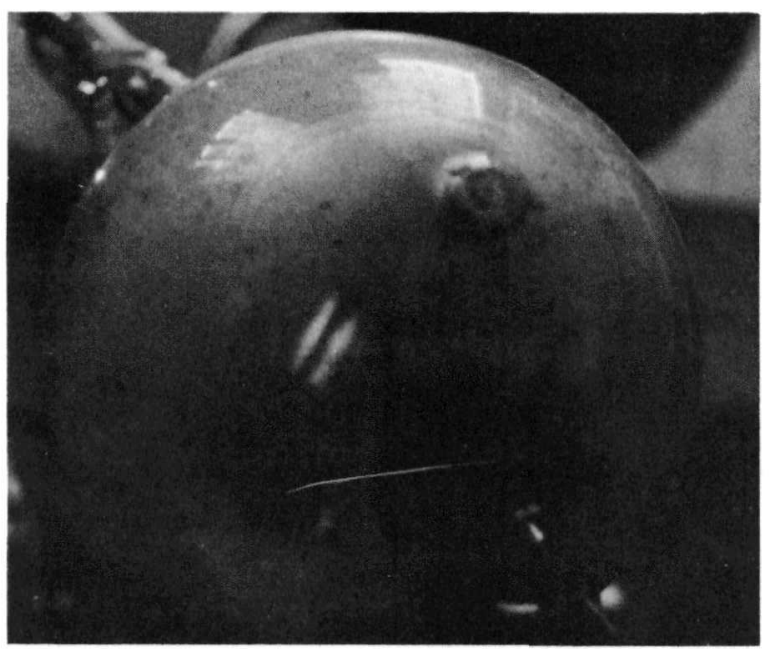

Fig. 2. Typical Emission Pattern from Graphite "Knife-edge" doublet pattern usually observed (even for aquadag) is difficult to understand. Some possible explanations are discussed below. The applied voltage at which such a pattern appeared varied from platelet to platelet, but usually fell in the range from 4 to $6 \mathrm{kV}$.

The results of some of the early attempts to remove oxide film from the surface by heating are shown in Figure 3 (a-d). It is readily apparent that even a relatively mild heating causes a multiplication of the pattern and that further heating intensifies this effect.

In a later series of experiments, attempts to remove the oxide film by "field desorption" at increasingly higher voltages were carried out. A typical sequence of patterns, as shown in Figure 4 (a-d), is closely reminiscent of the sequence obtained in the heat treatments.

In a few cases, the graphite platelets were bombarded by protons, oxygen, or mercury ions in an attempt to remove the oxide film without damaging the emitting edges. These attempts also proved fruitless.

The emission characteristics of the graphite platelets were monitored by measuring the emission current as a function of voltage applied to the anode. The results of the most successful run of this type are given in Figure 5 in which $\log \mathrm{I} / \mathrm{V}^{2}$ is plotted vs. $1 / \mathrm{V}$. According to the FowlerNordheim equation, (1) the slopes of these lines are proportional to the work function raised to the $3 / 2$ power. Figure 5 thus shows that the work function of the emitting platelet of graphite is increased by heating to $1075^{\circ} \mathrm{C}$, is unaffected by further heating to $1200^{\circ} \mathrm{C}$, and is drastically reduced by exposure to air.

The experiments in which the graphite platelets were heated to higher temperatures (up to $2000^{\circ} \mathrm{C}$ ) in a better vacuum gave very nearly the same results as those carried out at lower temperatures. A typical sequence of the patterns observed is shown in Figure $6(a-d)$. 


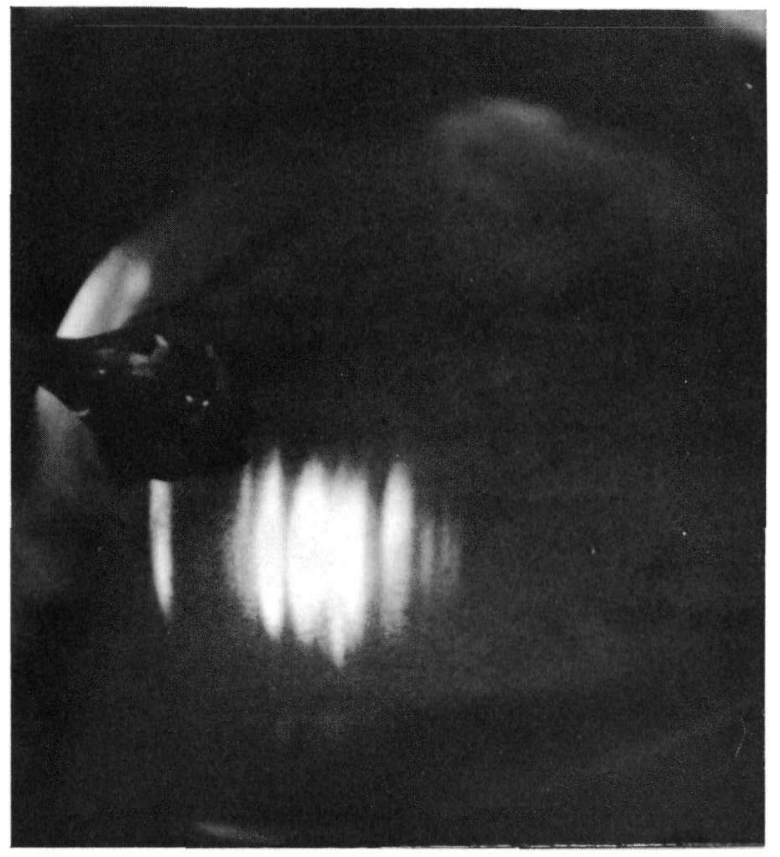

a. Heated to $600^{\circ} \mathrm{C}$

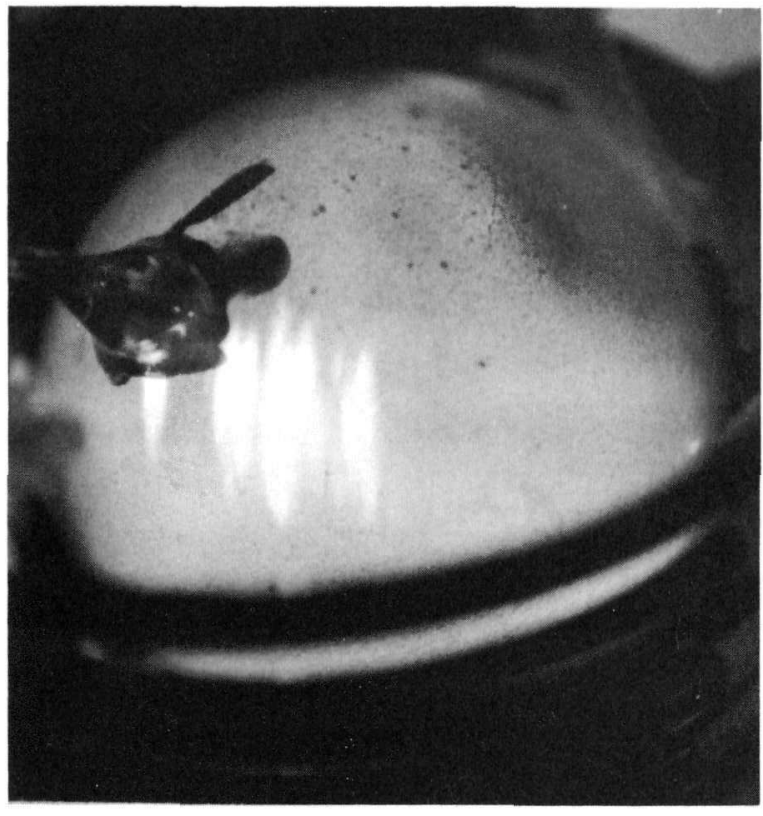

c. Heated to $840^{\circ} \mathrm{C}$

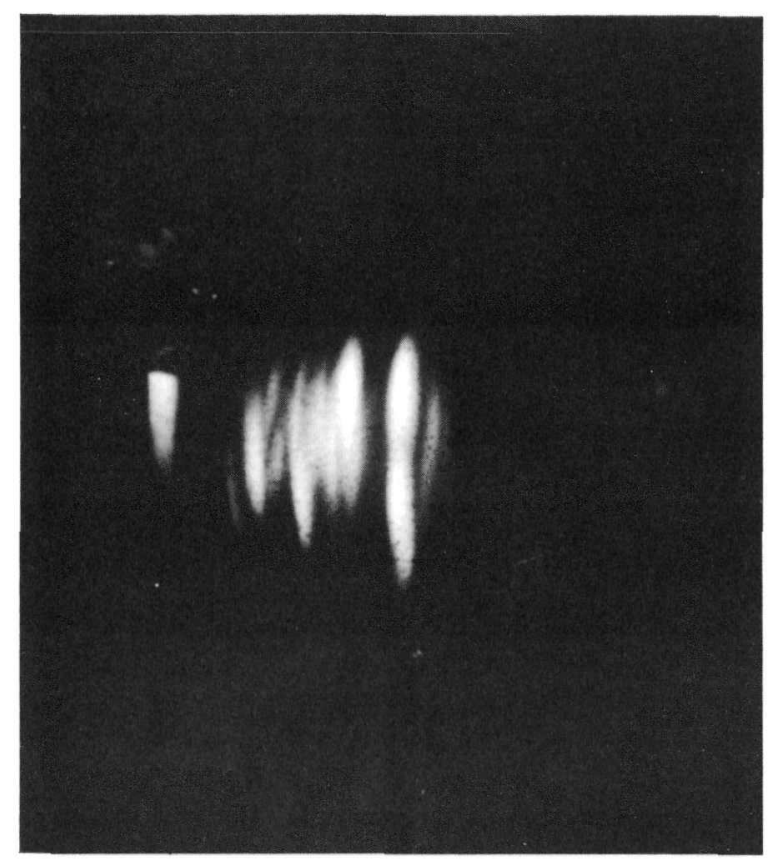

b. Heated to $789^{\circ} \mathrm{C}$

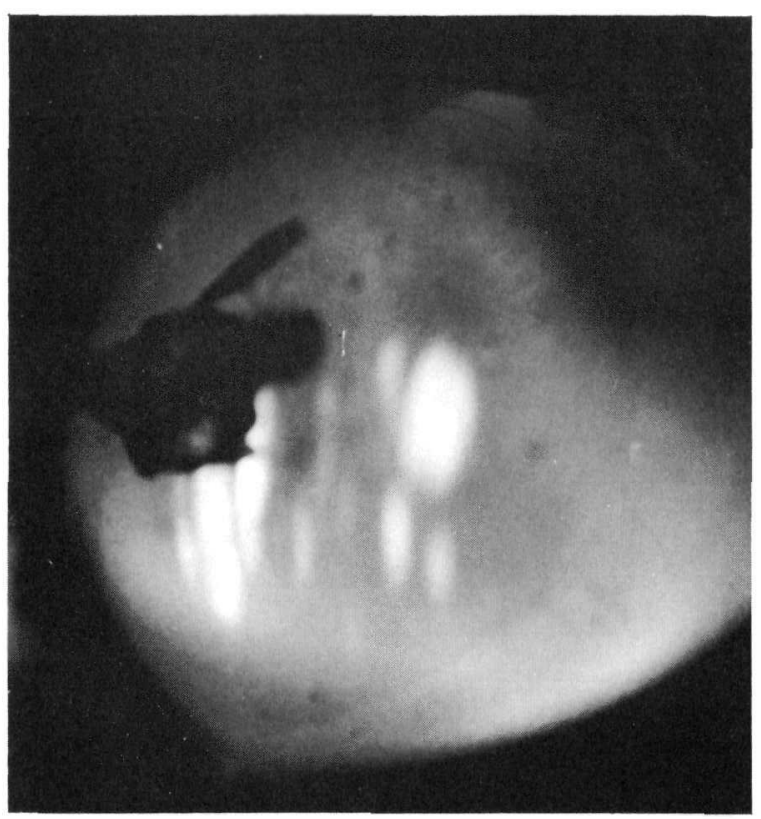

d. Heated to $990^{\circ} \mathrm{C}$

Fig. 3. Effect of Heating on Emission Pattern 


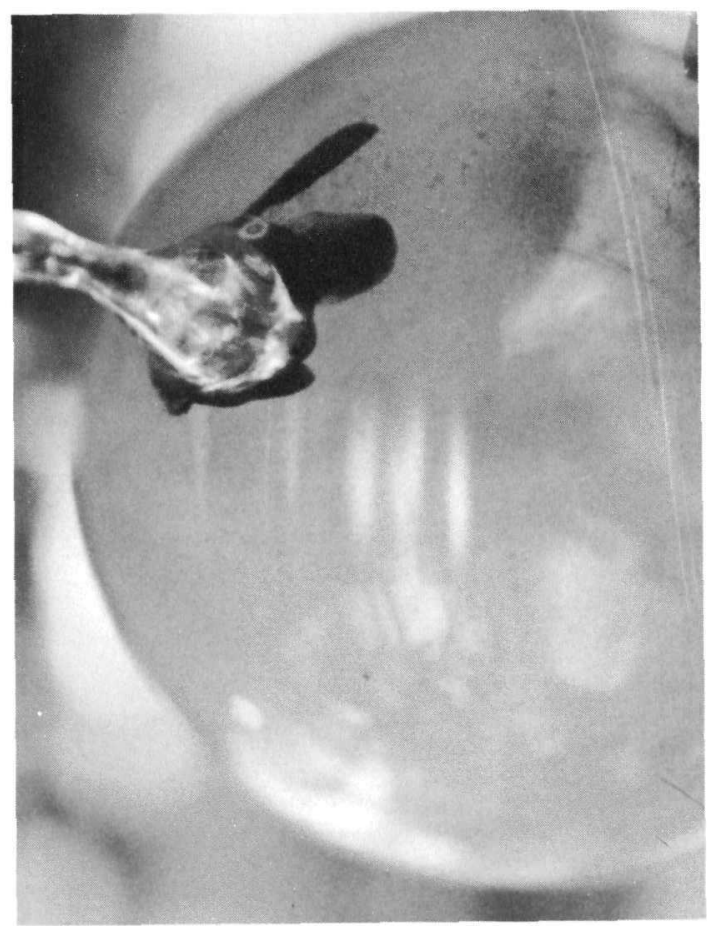

a. Emission at $6.7 \mathrm{kV}$

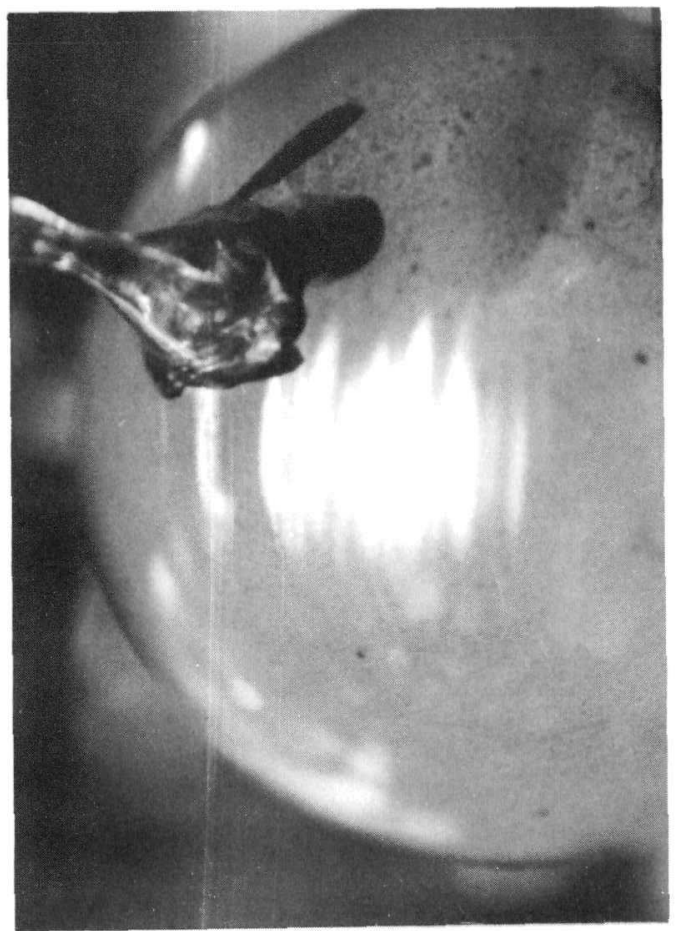

c. Emission at $8.5 \mathrm{kV}$

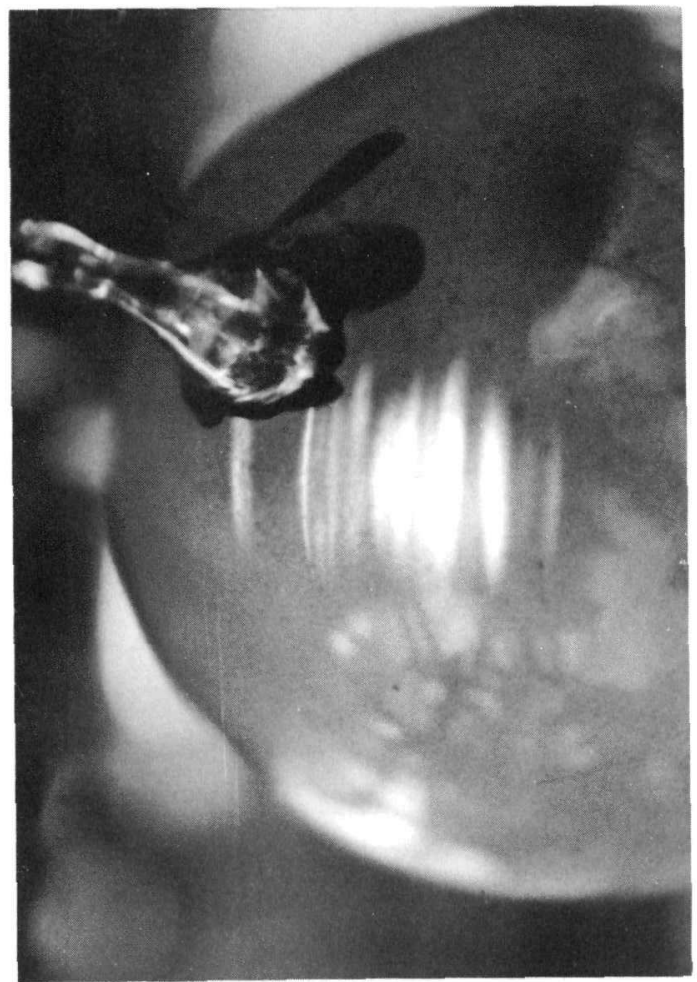

b. Emission at $7.9 \mathrm{kV}$

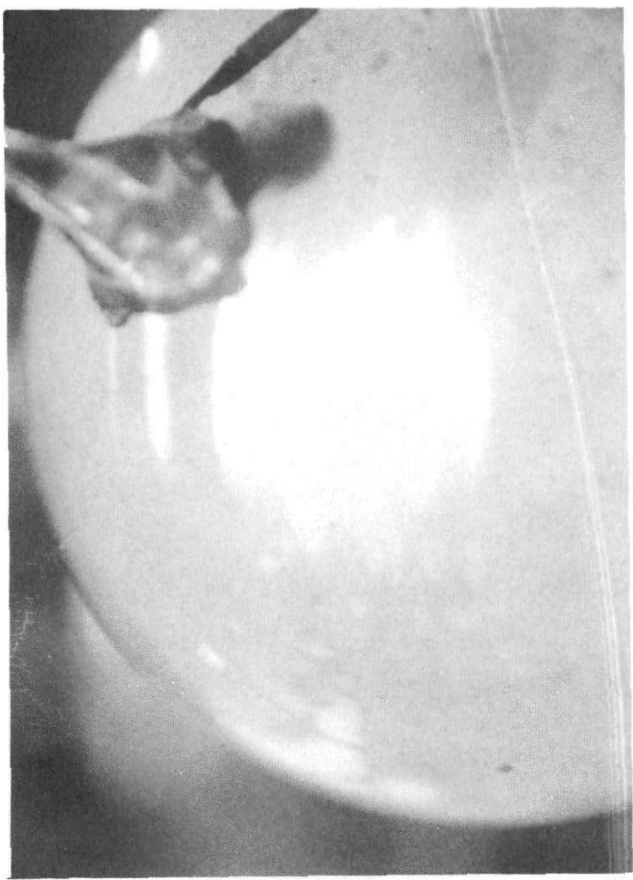

d. Emission at $9.3 \mathrm{kV}$

Fig. 4. Effect of Electric Field on Emission Pattern 


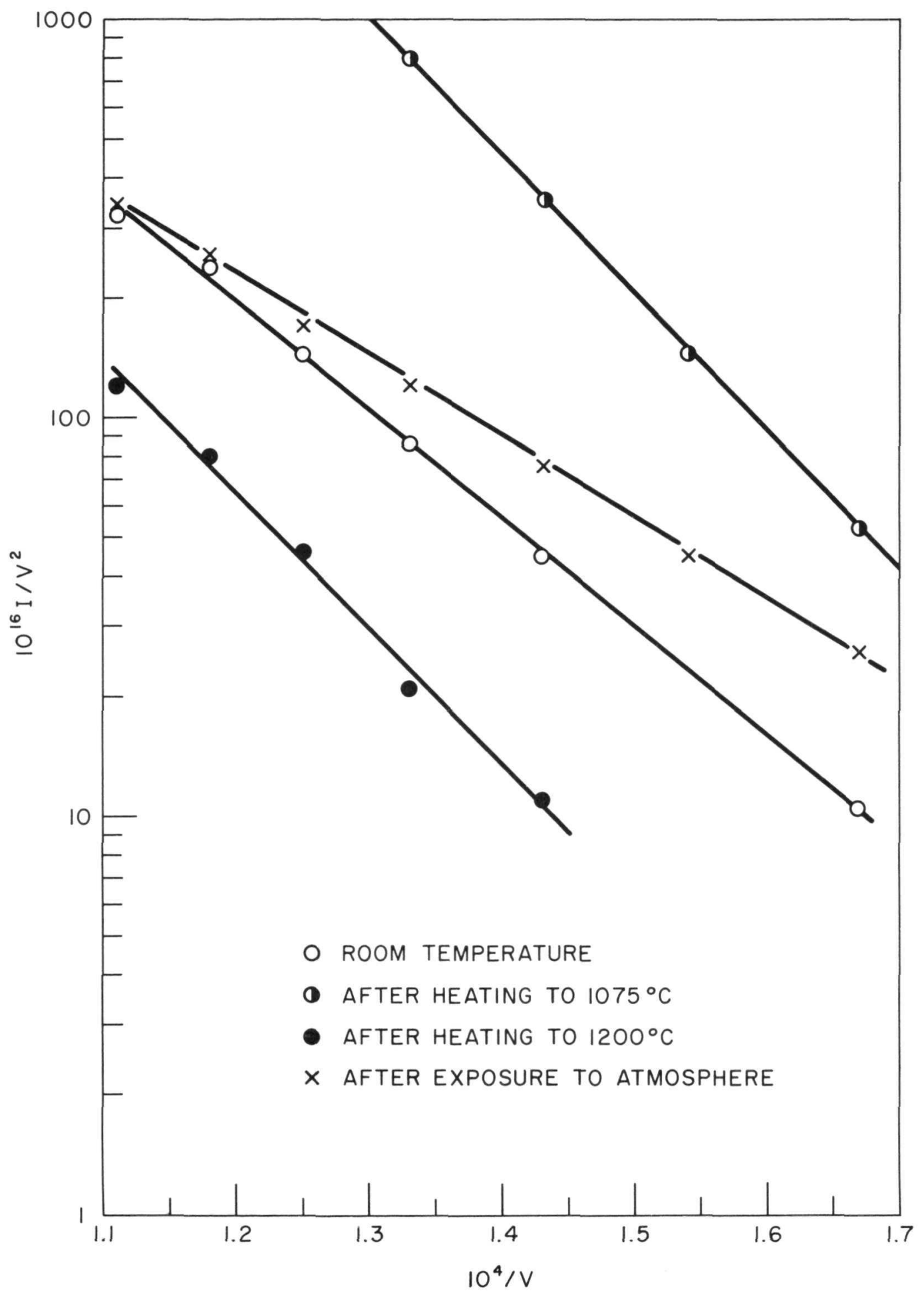

Fig. 5. Fowler-Nordheim Plot 


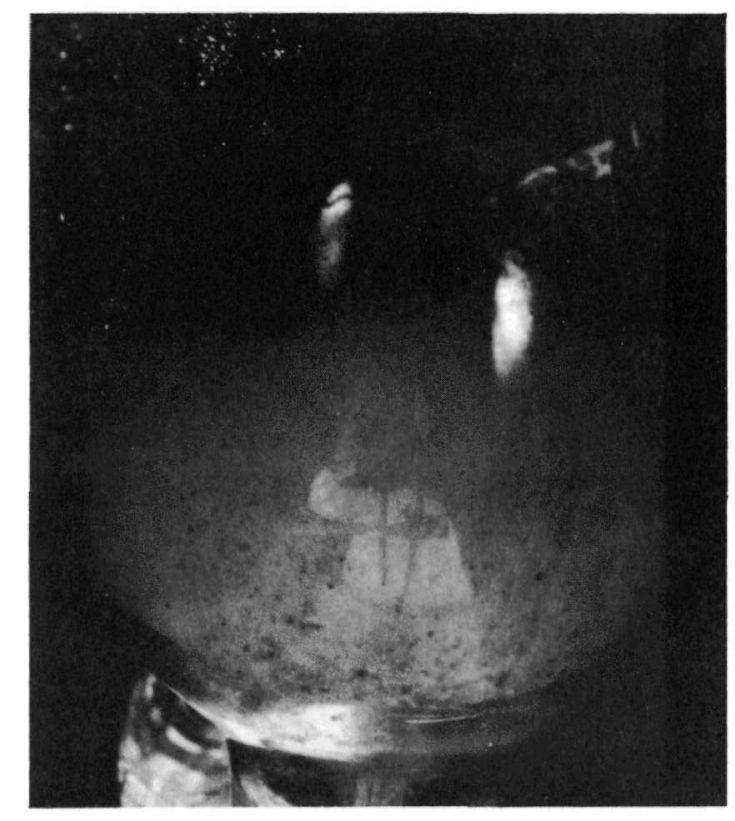

a. Heated to $900^{\circ} \mathrm{C}$

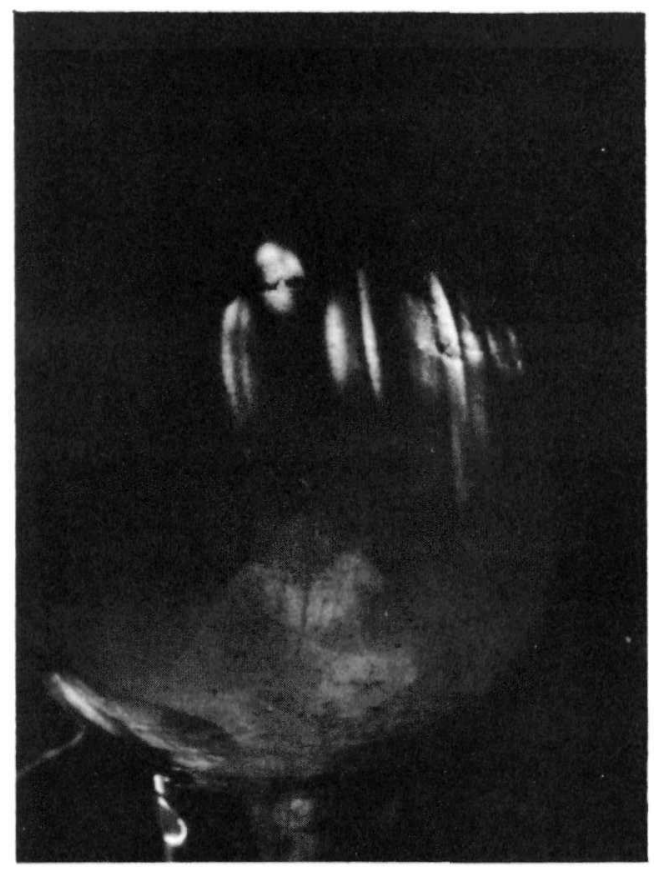

c. Heated to $1800^{\circ} \mathrm{C}$

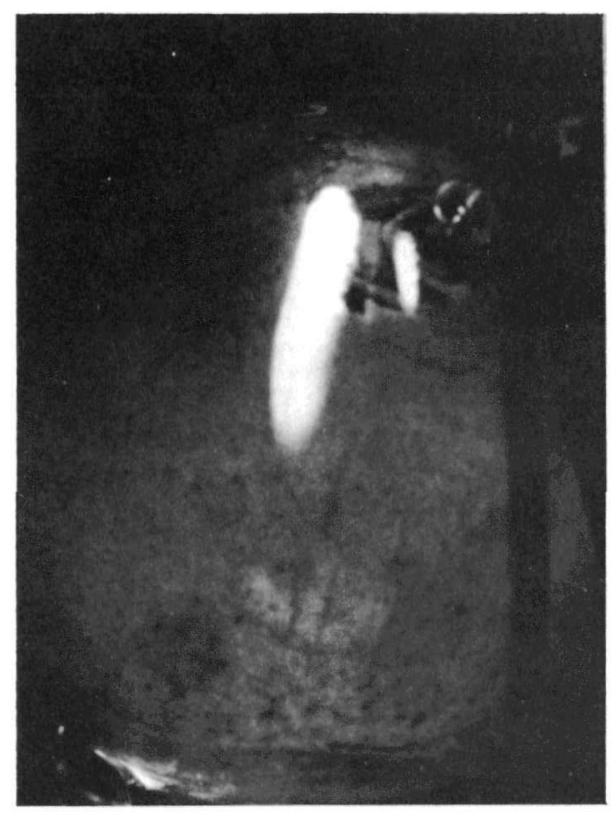

b. Heated to $1500^{\circ} \mathrm{C}$

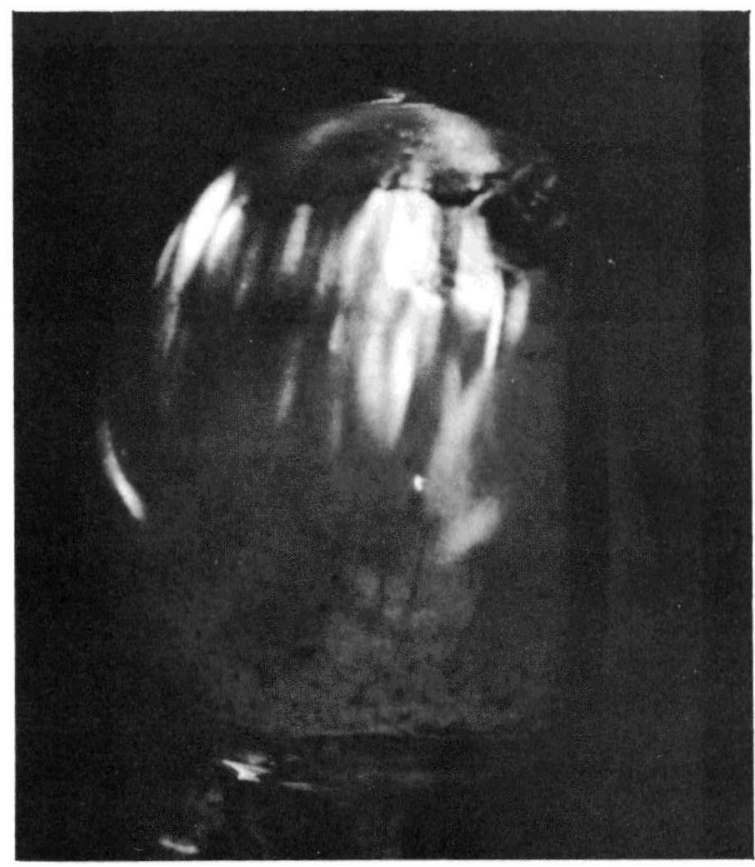

d. Heated to $2000^{\circ} \mathrm{C}$

Fig. 6. Effect of Heating on Emission Pattern 
In the course of the experiments, many attempts were made to "cycle" the conditions, that is, after cleaning the surface by heating to a high temperature in vacuo, oxygen was deliberately introduced to contaminate the surface once more and the pattern compared with the initial pattern observed before heat treatment. In all cases, the two patterns were different; an example is shown in Figure 7 (a-c). The failure of these cycling experiments renders difficult the interpretation of the data.

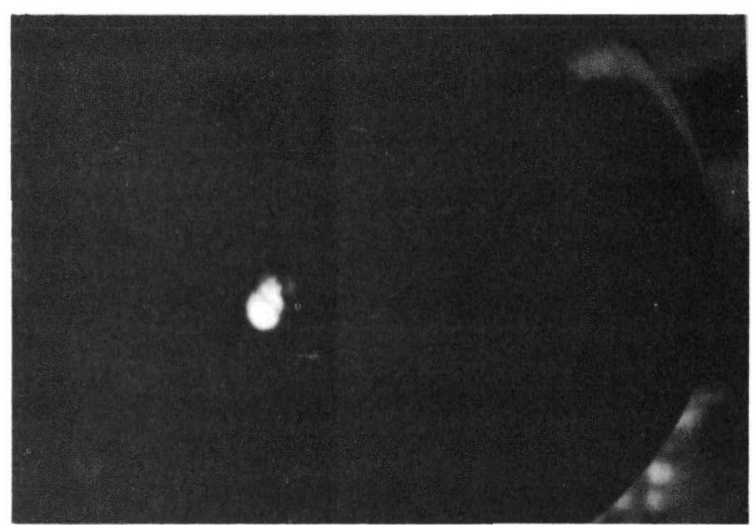

a. After Cleaning at $1200^{\circ} \mathrm{C}$

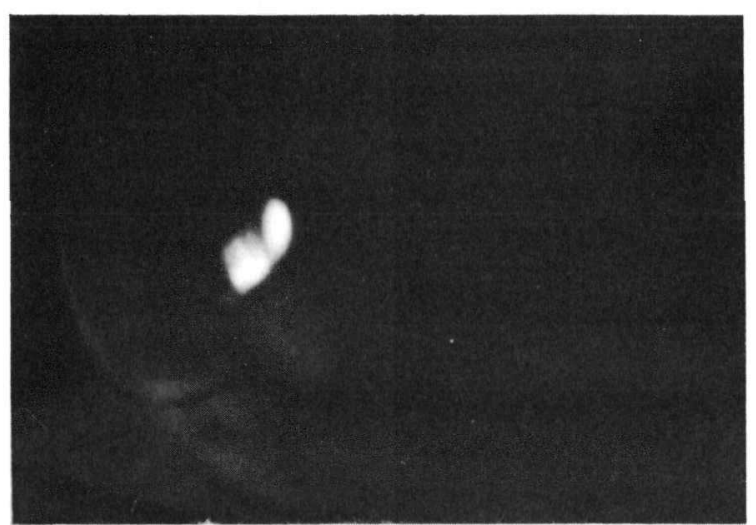

b. After Exposure to 1-micron Air Pressure

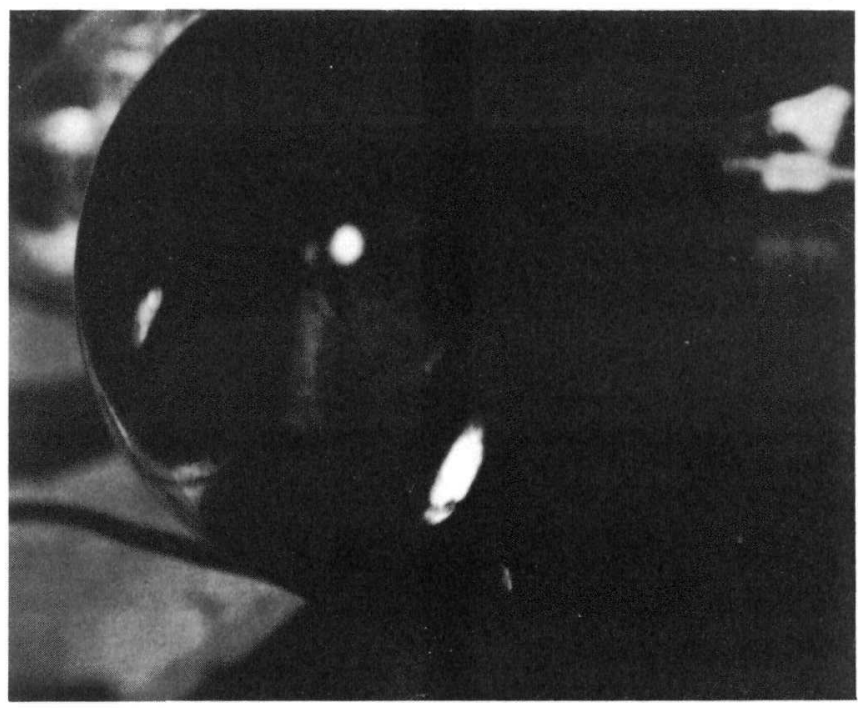

c. After Cleaning at $1200^{\circ} \mathrm{C}$

Fig. 7. Effect of Oxygen on Emission Pattern

In a further series of experiments, attempts were made to grow a graphite crystal (or whisker) on a sharply pointed tip of tungsten. A glow discharge, with the tip as anode, through a low pressure of carbon monoxide resulted in a deposit of carbon suboxide on the tip. After pumping 
down to a high vacuum, the tip was heated to a high temperature to convert the suboxide to carbon. It was hoped that a characteristic emission from graphite would be observed; however, in all cases but one, only the tungsten pattern was apparent. In one case, a hexagonally symmetric pattern, shown in Figure 8, was

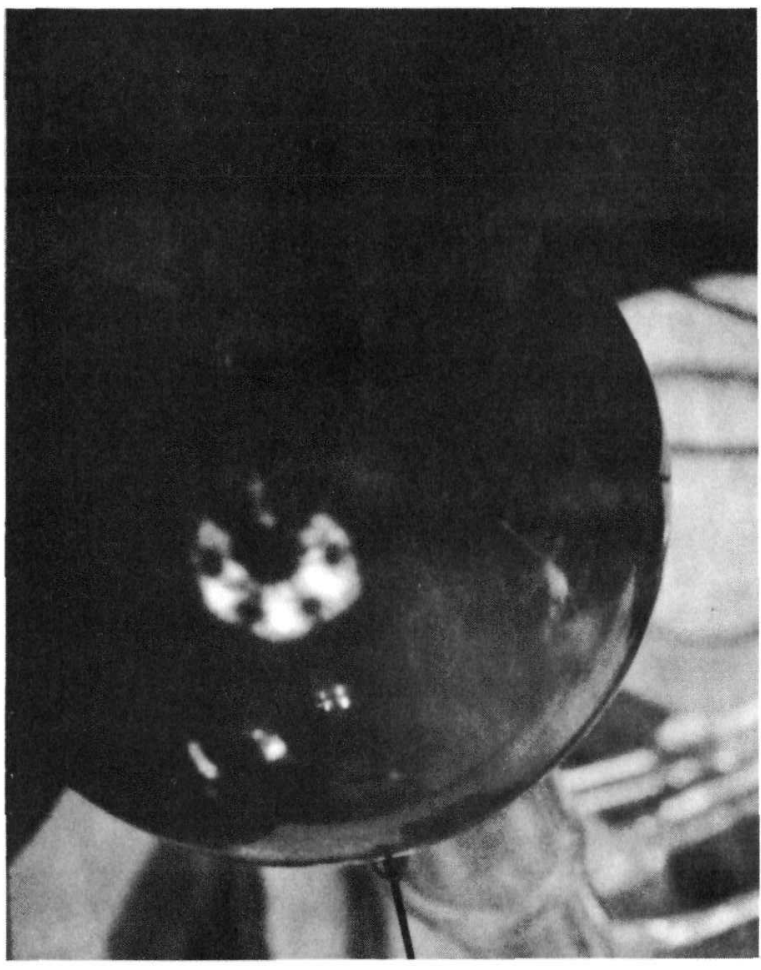

Fig. 8. Hexagonal Emission Pattern observed; this is probably due to emission from tungsten carbide, (7) which possesses hexagonal symmetry. Since tantalum carbide has cubic symmetry, the experiments were repeated with a tantalum tip as substrate; despite many variations in the experimental conditions, no hexagonal pattern was observed.

\section{DISCUSSION}

The patterns observed in field emission from knife-edges of graphite appear to have the rudimentary symmetry expected for emission from a linear source. The fact that doublets are commonly observed in the initial emission may be due to the "chair" structure of the platelets, that is, the edge surfaces developed during burning in dry oxygen are predominantly $[11 \overline{2} 0]$

and equivalent planes.(8) Doublets could conceivably result from electron emission from the corners of such a hexagonal face; however, it is difficult to see why emission should be suppressed along the straight edges, since these too are sharp in one dimension. The development of the satellite lines due to heat treatment or field desorption would then be a result of additional structure resulting from the above treatment. It is not clear whether such additional structure actually developed, since no evidence of formation was found upon optical microscopic examination of the platelets.

Evidence for the development of further structure is found when the platelets are further oxidized (in dry oxygen), and examined in an electron microscope. An electron photomicrograph of such an edge is shown in Figure 9; it is evident that many overlapping packets of graphite planes are present.

An alternative reason for the characteristic emission of a doublet may be the presence of a twin line running back perpendicularly from the surface. As was mentioned earlier, such twins are induced by the 


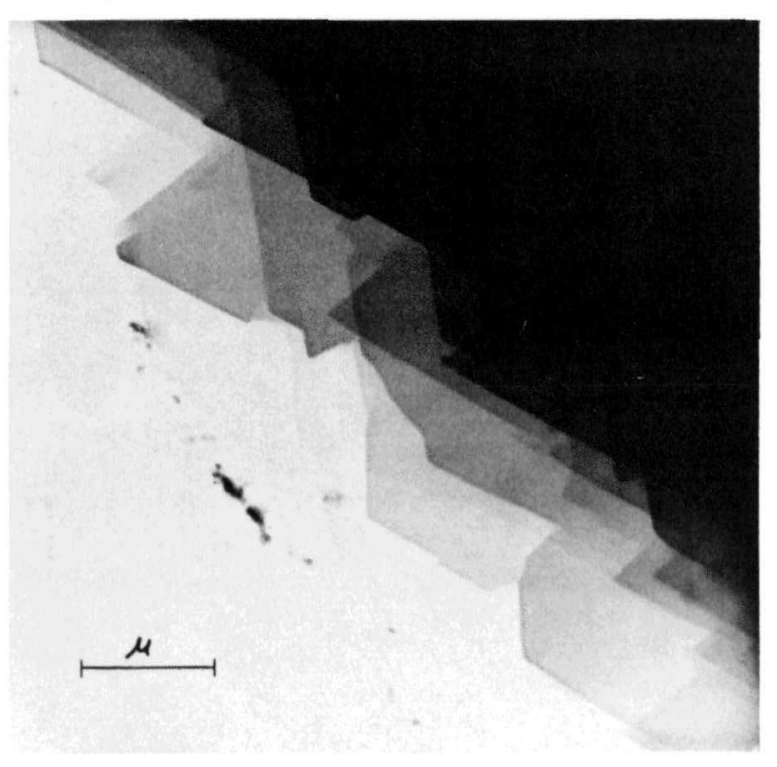

Fig. 9. "Developed" Structure of "Knife-edge" of Graphite clamping of the platelet; in addition, they are often observed in thin layers of graphite. (9) Such twin boundaries may lead to the formation of internal cracks via a mechanism suggested by Stroh. (10) Emission from the two edges of such a crack could result in the doublet so often observed, since the work function of graphite may be lowered by the occurrence of such cracks. The proliferation of lines resulting from heat treatment or field desorption could then be due to further formation of cracks.

The sudden changes which were sometimes observed in the emission patterns are, perhaps, due to the breaking up of packets of graphite layer planes into smaller

packets. This is made more plausible by the fact that a sudden increase in current frequently was observed to accompany the pattern change. Such breaking-up might be due to either of the mechanisms suggested above, or to electrostatic repulsions, evolution of occluded gases, etc.

The observed changes in emission patterns and in the slopes of the Fowler-Nordheim lines indicate that the oxygen absorbed on the surfaces of the graphite platelets is at least partially desorbed by the heat treatment. Unfortunately, it is impossible to decide whether the oxygen is completely removed because there is no characteristic symmetrical pattern observed. The experiments would be much more definitive in this regard if it were possible to view the pattern resulting from emission of electrons in the c-direction of the graphite lattice, but inducing such emission appears to be very difficult. The extent of the reabsorption of oxygen in the "cycling" experiments similarly cannot be evaluated due to the ir reversible changes which take place in the pattern during desorption.

There is independent evidence( 11 ) that essentially all of the externally absorbed oxygen is removed by heating graphite to about $900^{\circ} \mathrm{C}$. This being the case, the data of Figure 5 may be interpreted as follows: the graphite knife-edge is covered by a chemisorbed layer of oxygen or carbon monoxide (and, presumably, several physisorbed layers which, however, are removed by the vacuum system) after preparation as described above; heating the edge to $1000-1200^{\circ} \mathrm{C}$ removes the chemisorbed gas, so that the large negative slopes correspond to the work function of an essentially clean graphite surface; exposure of this surface to air 
results in the reabsorption of oxygen and a lowering of the work function. The fact that the slope of the Fowler-Nordheim line is lowest after the reabsorption of gas may be explained by the presence of a complete monolayer, whereas the sample preparation may result in only partial coverage or perhaps in coverage by a mixture of chlorine and oxygen.

It is generally observed(2) that a chemisorbed layer of oxygen on a metal increases the work function of the metal surface; just the opposite effect is observed here. This may be due to a qualitative difference in the type of chemical bonding in the chemisorption. The metal-oxide bond results in a dipole layer on the surface, which increases the work function; the carbon-oxide bond is nonpolar (or, perhaps, as suggested by these experiments, polarized in the opposite sense) and does not affect the work function, which may then be decreased by secondary causes. Furthermore, it must be realized that the changes in slope of the Fowler-Nordheim lines may be due to spurious effects, such as field enhancement due to charge exchange and polarization, or to an unobserved increase in the emitting area; the lack of a reproducible pattern makes it impossible to rule out these various possibilities.

If it is assumed that emission corresponding to a clean graphite surface was observed in the experiments plotted in Figure 5, it is possible to derive values of the work functions from the slopes by using the "best value" of $4.60 \mathrm{eV}$ for clean graphite to calibrate the system. In this manner we obtained $3.93 \mathrm{eV}$ for the freshly prepared surface and $3.25 \mathrm{eV}$ for the surface exposed to air. It is theoretically possible(l) to derive the work function from the slopes of the Fowler-Nordheim lines by calculating the field strength from the observed voltage and the radius of the emitting tip. This procedure is satisfactory for well-defined hemispherical tips, but fails utterly for a ragged knife-edge of graphite with an unknown effective radius.

The intercepts of the Fowler-Nordheim lines at very high fields should all have the same value if one assumes that the work function is not a function of the field strength. This is approximately the case for the lines of Figure 5, except for the uppermost; the fact that this lies well above the other three lines is probably to be interpreted as an enhancement of emission due to an increase in emitting area - perhaps a protrusion developed by the heat treatment. It will be noted that further heating brought the emission back to the proper range - perhaps by removing the protrusion.

It is believed that migration of atoms on the surface of graphite takes place at temperatures above $1500^{\circ} \mathrm{C}$. (12) It would be interesting to confirm this by investigating the rounding of the tip of a graphite emitter. It apparently is possible to heat a graphite tip to a sufficiently high temperature, but the irreversible changes of the pattern discussed above make it impossible to observe any rounding of the tip. 
Field emission from whiskers of various substances, even mercury, has been observed,(13) and presumably could be observed with graphite whiskers. The scroll-like nature(14) of the graphite whisker, however, makes it very likely that such emission, if observed, would be from the edge of layer planes and, hence, similar to that discussed above. It was for this reason that an attempt was made to grow a small crystallite of graphite on a metallic substrate; it was hoped the emission in the cdirection could be observed. No success was attained in these intricate experiments.

\section{REFERENCES}

1. R. H. Good, Jr. and E. W. Müller, Handbuch der Physik (S. Flugge), Vol. XXI, pt. 1, 176 (1956).

2. R. Gomer, Field Emission and Field Ionization, Harvard University Press (1961).

3. E. W. Mulller, Article in W. G. Berl, Physical Methods in Chemical Analysis, Vol. 3 , Academic Press (1956).

4. R. Klein, J. Chem. Phys. 22, 1406 (1954). R. Klein and L. B. Leder, J. Chem. Phys. 38, 1863 (1963).

5. G. R. Hennig, Proc. 4th Carbon Conference (1960), Pergamon Press, p. 145 .

6. F. Laves and Y. Vaskin, Z. Krist., 107, 337 (1956).

7. E. W. Müller, Ergeb. exakt. Naturwiss. 27, 290 (1953).

8. G. R. Hennig, Proc. 5th Carbon Conf. (1962), Pergamon Press, p. 143.

9. R. Bacon and R. Sprague, Symp. on Direct Observation of Imperfections in Crystals (1962), John Wiley, p. 357.

10. A. N. Stroh, Phil. Mag. $\underline{3}, 597$ (1958).

11. H. Hering, Proc. 6th Carbon Conf. (to be published).

12. M. A. Kanter, Phys. Rev. 107, 655 (1957).

13. R. Gomer, J. Chem. Phys. 28, 457 (1958).

14. L. Meyer, Proc. 3rd Carbon Conf. (1959), Pergamon Press, p. 457. 